\title{
La ética del discurso en la filosofía con niñas y niños
}

Anca-Nicoleta Rotila

al285623@uji.es 
I. Resumen

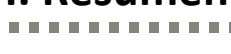

En este estudio vamos a intentar determinar en qué medida la filosofía con niñas y niños sigue las mismas normas que se determinan en la ética del discurso, así como decidir si dicho método filosófico cuenta con una eficacia cultural. Para responder a nuestra pregunta nos hemos centrado en el análisis de investigaciones de las autoras Haynes, Nos, Irando y Ferné, entre otras no menos importantes. Así, a lo largo del texto se podrá ver claramente la estrecha relación entre la filosofía con niñas y niños y la ética del discurso, que se muestra en la importancia del diálogo, de la búsqueda de una comunidad comunicativa ideal y el no perseguir objetivos individuales o estratégicos. De igual manera, la filosofía con niñas y niños cuenta con la eficacia cultural, ya que empuja a los más pequeños y a las más pequeñas hacia el pensamiento reflexivo sobre el bien común.

Palabras clave: filosofía, niñas, niños, ética, discurso, eficacia cultural.

\section{Introducción}

La filosofía con niñas y niños considera y apoya que las y los infantes tienen sentido crítico, contrariamente a lo que desde Occidente se ha inculcado. De esta manera, en estas clases de filosofía se sigue la metodología del diálogo que, como sabemos, es la base de la ética del discurso. No obstante, la filosofía con niñas y niños también se presenta como una reflexión activa, por lo tanto analizaremos su eficacia cultural.

Dicho esto, el objetivo que se persigue en este escrito es determinar en qué medida la filosofía con niñas y niños sigue los mismos pasos que la ética del discurso y averiguar si esta filosofía tiene, o consigue, una eficacia cultural.

A lo largo del texto hablaremos de la fundamentación del tema, es decir, de aquello que ya se ha escrito. En el siguiente paso, enumeraremos la metodología que utilizaremos para el análisis de nuestro tema. A continuación, detallaremos los resultados obtenidos del análisis de los textos utilizados. Seguidamente, en la discusión, analizaremos, por una parte, si la filosofía con niñas y niños sigue las mismas pautas de la ética del discurso en sus clases. Además, vamos a hablar sobre la eficacia cultural de esta filosofía. Por último, haremos una pequeña reflexión a modo de conclusión. 


\section{Fundamentación}

Aunque la asociación entre la filosofía con niñas y niños y la ética del discurso no se ha hecho, la ética del discurso sí que ha estado analizada en varias ocasiones por su influencia en otras temáticas. Una de estas es la ética de la liberación sobre la que Enrique Dussel ha escrito en su artículo "La ética de la liberación ante la ética del discurso». En este texto, el autor se basa en el trabajo de Karl-Otto Apel "La ética del discurso ante el desafía de la filosofía de la liberación» para analizar la objeciones que este hace. Con otras palabras, estas dos disciplinas son puestas en discusión para averiguar cómo se influyen una a la otra (Dussel, 1996).

Otro texto en el que se compara un tema con la ética del discurso es el artículo de Juan Carlos Siurana "La ética del deporte desde la justicia como igualdad de oportunidades en la ética del discurso». En este texto se explica la importancia de la ética del deporte para que, ulteriormente, se hable sobre la influencia de la ética del discurso en el deporte, considerando la justicia como igualdad de oportunidades (Siurana, 2007).

En cuanto a la eficacia cultural, según la investigación sobre los escritos publicados en relación con este tema, solo se han encontrado textos que hablen de la eficacia cultural en el medio de la comunicación. Sin embargo, en este trabajo hablamos de la eficacia cultural de una disciplina educativa como es la filosofía con niñas y niños.

\section{Metodología}

Como hemos dicho anteriormente, el objeto de estudio es, por una parte, ver en qué medida la filosofía con niñas y niños sigue las mismas pautas que la ética del discurso. Para ello, lo primero que se ha hecho ha sido analizar textos en los que se explique el objetivo de la filosofía con niñas y niños y su desarrollo en clase, o la aplicación que tiene. Uno de los textos revisados ha sido el libro de Johanna Haynes Los niños como filósofos. El aprendizaje mediante la indagación y el diálogo en la escuela primaria. El segundo escrito fue el artículo de Guillermina Ferrer Rodríguez «Filosofía con niños. Como acercar la filosofía a niñas y niños».

Por otra parte, para el análisis de la ética del discurso, se ha revistado un apartado de la tesis de Sonia París Albert "La transformación de los conflictos desde la Filosofía para la Paz». En este capítulo de la tesis, la autora explica la ética del discurso para aplicarla a la resolución de los conflictos. En este texto se han buscado cuáles son los pilares básicos sobre los que se sustenta esta ética. 
Por último, para hablar sobre la eficacia cultural me he basado

en el artículo de las autoras Eloísa Nos, Amador Irando y Alessandra Ferné «La eficacia cultural de la comunicación de las ONGD: los discursos de los movimientos sociales actuales como revisión». En este texto se explica muy bien qué es la eficacia cultural para poder aplicarla, también, a otras disciplinas o temáticas.

Después de la lectura de los textos, se han extraído los resultados deseados y, ulteriormente, las tres temáticas analizadas puedan ser puestas en discusión una con la otra.

\section{Resultados}

\subsection{La filosofía con niñas y niños}

Como se ha dicho en el apartado anterior, en el análisis del libro de Johanna Haynes y del artículo de Guillermina Ferrer Rodríguez, se ha buscado información sobre qué es la filosofía con niñas y niños y los objetivos que persigue, el desarrollo de estas clases y las pautas comunicativas que se emplean en ellas. Comentamos todas estas cuestiones a continuación:

Actualmente, la filosofía se ve como un estudio meramente académico y elitista, a cuya terminología compleja pocos pueden acceder. De esta manera, la filosofía se aprende en las aulas de memoria pero en muy pocos casos se aprende realmente a filosofar. Por eso, en 1970 se ponen las bases del proyecto «Filosofía con niños", que lleva a cabo el profesor y autor Lipman. El propósito de este proyecto fue "ayudar al estudiantado al desarrollo de una actitud crítica y la necesidad de participación activa» (Ferrer Rodríguez, 2012: 23). En cuanto a la metodología, esta tiene como pilares básicos el diálogo y la creatividad. Es más, la filosofía con niñas y niños apoya el artículo 12 de la Convención de las Naciones Unidas sobre los Derechos del Niño por el que se explica que se debe dejar al niño y a la niña a que expresen sus opiniones libremente y a que formen sus propias maneras de pensar, su proprio juicio; con otras palabras: que se tengan en cuenta sus opiniones, claramente, en función de su edad y madurez. Esto les permitirá participar de forma activa en sus comunidades y naciones (Haynes, 2004: 35).

No obstante, como bien sabemos, en torno al estímulo del pensamiento crítico, hoy en día solo se escucha hablar en las aulas de cursos más avanzados, como las de bachillerato o -y sobre todoen la universidad. Sin embargo, el pensamiento crítico debe ser una cualidad que se ha de trabajar desde una edad temprana. Contrariamente a lo que muchos piensan, los niños y las niñas nacen con capacidad de crítica, lo que significa que el pensamiento adulto, occidental, se equivoca al decir que los adultos son los que les deben transmitir los conocimientos, la manera de pensar o las ideas. Esta 
es, sin duda, un fomento de la educación bancaria de la que Paulo

Freire tanto nos hablaba. Sin embargo, la pregunta surge en torno a si verdaderamente tanto los padres como los profesores y las profesoras siguen este patrón a la hora de interaccionar con los infantes.

Al mismo tiempo, la autora Ferrer Rodríguez nos habla del significado que tiene la filosofía para Lipman, como «una actividad reflexiva que se realiza tanto individual como conjuntamente» (Ferrer Rodríguez, 2012: 23). Con esto entendemos que se parte desde lo personal, la búsqueda de respuestas a las preguntas personales, siempre acompañado por los profesores y las profesoras, así como, por los compañeros y las compañeras. Al hablar de una clase, nos referimos a un espacio en el que convive una multitud de culturas, etnias y religiones, lo que ofrece diversidad de percepciones del mundo y maneras de argumentar. No obstante, la diversidad de temáticas abordadas tendrá como resultado contradicciones, pero también reconciliaciones (Ferrer Rodríguez, 2012: 24-25).

Johanna Haynes también respalda este argumento al decir que en clase, a la hora de trabajar un tema concreto -como hablar sobre la muerte- es importante empezar por un cuento que ayude a los niños y a las niñas a empatizar con el personaje y a conectar con sus vivencias personales (Haynes, 2004: 25-26). El método socio-afectivo, según mi punto de vista, hace que los niños puedan entrar mejor en la historia. Y lo mismo ocurro con preguntarles lo que les haga pensar en qué harían ellos, que deberían hacer los personajes, etc. Es más, es importante animarlos a que hagan ellos las preguntas.

A medida que van adquiriendo más seguridad en sí mismos, los niños dejan de plantear preguntas únicamente al adulto. Valoran cada vez más la oportunidad de discutir entre ellos los asuntos importantes. Cada vez se preocupan más de plantear cuestiones que tengan algo que ver con sus propias vidas. (Haynes, 2004: 29)

Así pues, el planteamiento de la filosofía con niñas y niños empieza necesariamente con cuestiones que ellos plantean, a partir de un estímulo previo, como una historia, un cuento, una imagen, etc. Al plantearse todas las preguntas, el debate se focalizará en aquellas escogidas de acuerdo a un proceso democrático. Se persigue que los niños y las niñas piensen de una manera lógica y crítica, pero sobre todo $-y$ es algo que ellos y ellas lo saben hacer perfectamente pero que con el paso del tiempo se pierde-, a pensar de una manera creativa. El objetivo final que se persigue no es que los infantes colaboren para llegar a una conclusión que obtenga unanimidad de apoyos a favor, sino que colaboren para llegar a la verdad a través de la diversidad de opiniones. Todo esto ayuda al desarrollo de la autoconciencia y la flexibilidad personal, entre otras muchas más aportaciones (Haynes, 2004: 33). Esta filosofía se 
plantea como una actividad en la que la clase se establece en círculo, de manera que todos puedan verse las caras y estar comunicados.

...se pretende conseguir una comunicación eficaz y buenas relaciones en el aula, así como ofrecer un foro en el que se puedan abordar los problemas con talante constructivo. Se anima a los niños a que exploren sus sentimientos, a que escuchen a sus compañeros, a que hablen por turno y a que busquen soluciones (Haynes, 2004: 32)

No obstante, lo que sí que tiene que quedar claro es que un debate filosófico con niñas y niños sigue los mismos requisitos que cualquier otro debate imparcial, en el que se pide la escucha atenta, la no interrupción de los discursos de los demás, ni la imposición de ideas o cualquier forma de ridiculización o falta al respeto de cualquiera de los miembros del grupo. En cuanto al profesorado, este debe escuchar a los niños y a las niñas, pero al mismo tiempo, encontrar formas originales y creativas para lograr que el alumnado también le escuche y que, ulteriormente, se pase a la acción (Haynes, 2004: 93). No hay que olvidar que hoy en día estamos intentando educar niños que pertenecen a una sociedad movida por las innovaciones tecnológicas mediante métodos tradicionales de enseñanza, lo que se debe revisar y cambiar.

Para concluir este apartado cabe decir que entre los objetivos de la filosofía con niñas y niños se puede encontrar que se promueve el razonamiento reflexivo y el pensamiento más allá de lo individual abarcando el bien común (Ferrer Rodríguez, 2012: 25). Además, encontramos que genera el juicio crítico entre los jóvenes, pero, sobre todo, les impulsa hacia pensar por sí mismos. También, les ayuda a hacer uso de la reflexión para encontrar sentido a sus experiencias de vida. Por último, fomenta la comunicación, un aspecto fundamental entre los jóvenes (Ferrer Rodríguez, 2012: 29).

\subsection{La ética del discurso}

Como se ha mencionado anteriormente, a continuación se enumerarán los resultados sobre el análisis del texto de la autora Sonia París Albert. No obstante, me gustaría empezar este apartado con la definición de diálogo que el autor Vicent Martínez Guzmán (2004: 302) nos ofrece:

Acción de comunicarse dos o más personas pidiéndose o dándose razones de por qué se hacen, dicen o callan, lo que se hacen dicen o callan. Etimológicamente proviene del griego diálogos que, a su vez, viene del verbo dialégomai que significa hablar, decir, conversar. Es una palabra compuesta de la preposición dia como prefijo que significa "a través de» y de logos que significa, palabra, razón, discurso [...] Así «diálogo» es algo que nos hacemos dos o 
más personas, a través de las palabras, de las razones que nos

damos, de los discursos e, incluimos, de los silencios comunicativos.

Según las palabras del autor podemos ver que, en la ética del discurso, cada uno tiene la responsabilidad sobre todo aquello que dice, hace o calla. También, el otro como receptor, debe mostrar atención y disposición para comprender aquello que se le comunica a través de gestos, palabras y silencios.

Partimos de la premisa que dos personas, cuando empiezan un diálogo, establecen su relación, la definen. Teniendo en cuenta que toda la vida de las personas se define a través de sus relaciones, podemos decir que no se puede no comunicar. "Así, observamos la comunicación como un acto inherente a las relaciones humanas, parte de nuestra conducta y que tiene diferentes consecuencias en función de cómo sea utilizado» (París Albert, 2005: 177). Decimos pues, que la comunicación tiene entre sus premisas la empatía, el reconocimiento, el entendimiento mutuo y la búsqueda de la verdad.

Así pues, a continuación describimos los puntos más importantes a seguir -según la ética del discurso- para que se llegue a una buena y mejor comunicación. El primer punto $y$, sin duda, uno de los más importantes, es la escucha activa. Esto implica un esfuerzo por parte del receptor para entender el contexto de aquello de lo que se habla y las emociones y percepciones del emisor. El segundo es que uno de los propósitos más importantes del emisor sea hacerse entender, ya que muchas veces, por falta de compromiso con aquello que queremos comunicar o por falta de paciencia con la capacidad de comprensión del receptor, no prestamos suficiente atención a un objetivo tan importante como es el de hacernos entender. Otro caso que se suele dar es que los actores de la acción comunicativa presten mayor atención al hecho de afirmar su posición en la discusión que a la comprensión recíproca. Asimismo, es importante hablar desde nuestro punto de vista, sobre nuestros propios pensamientos y creencias, y no opinar sobre el otro, sobre sus actuaciones o convicciones. No obstante, tener un objetivo claro, preestablecido, de aquello que quieres decir tiene mucha importancia. Eso ayuda a no perder el hilo conductor de la conversación, así como, a poder seguir las ideas que queremos exponer y a que nuestro receptor nos pueda entender con más facilidad. Por último, uno de los puntos que personalmente considero de mayor relevancia es «...hacer ajustes que tengan en cuenta las diferencias de personalidad, sexo y cultura» (París Albert, 2005: 178).

Sin embargo, aparte de aquello que nos decimos a través de la comunicación oral, de las palabras, también hay que prestar atención a la comunicación no verbal como los silencios o la gesticulación. Estos dos recursos juegan un papel significativo, y más aún cuando el 
silencio, según en qué circunstancias se utilice, puede tener unas consecuencias más o menos positivas. Esta idea del silencio se puede relacionar muy bien con la idea de interpelarnos unos a otros. Y la capacidad de interpelarnos significa que podemos pedirnos cuentas o pedirnos explicaciones por aquello que nos decimos, hacemos o callamos, en este caso. La interpelación en el silencio tiene que ver con la responsabilidad que asumimos a la hora de callarnos cosas. "Cualquier cosa que hacemos, decimos o callamos nos compromete, nos liga con los y las otras interlocutoras de tal forma que siempre podemos pedirnos cuentas y exigirnos nuestra responsabilidad» (París Albert, 2005: 180).

Siguiendo la misma línea, hay que decir que, en la ética del discurso, los mismos participantes son los que deben crear las normas que se han de cumplir para la buena comunicación y el buen desarrollo del discurso argumentativo. Esto garantiza la adecuación situacional de los afectados. Basándose en el consenso y el reconocimiento mutuo, las normas deben ser aceptadas por todos y cada uno de los afectados (París Albert, 2005: 184). No hay que olvidar que se busca una comunidad comunicativa ideal, pero, al mismo tiempo, una comunidad comunicativa real.

Avanzando en la idea, según la teoría de los actos de habla de Asutin y Searle, decir algo es realizar una acción. Por esto, entendemos que el acto de habla es una acción que tiene como finalidad el entendimiento. Sin embargo, para que el entendimiento entre todos los afectados se dé, se han de cumplir las pretensiones de validez del habla, que empiezan con el hecho de que el receptor entiende que el mensaje del emisor es verdadero, el mensaje es inteligible, la forma de realizar el mensaje es correcta y también que el receptor crea en la veracidad de la intención del emisor (París Albert, 2005: 185).

Otro punto relevante es el principio de universalización dentro de la ética del discurso. Según este, ninguna de las normas de las que hablamos anteriormente, se tomará como máxima, sino que se universalizará o ajustará según las circunstancias de afectado. Así pues, en el acto de la comunicación se aceptarán personas que saben que es el bien, que saben que es la justicia y que «...se entienden a sí mismas como la fuente de pretensiones legítimas y aceptan las condiciones de la cooperación equitativa» (París Albert, 2005: 186). Solo pueden entrar en la argumentación aquellos que garantizan la igualdad de derechos entre los participantes y la veracidad de sus aportaciones. Para concluir con esta idea, gracias al principio de universalización, solo se aceptaran las normas que benefician por igual a todos los afectados, y todo esto siguiendo el objetivo del reconocimiento recíproco (París Albert, 2005: 186).

No obstante, si definimos la acción comunicativa, esta tiene como pilar base el entendimiento lingüístico. Así, los afectados se 
dedicarán a cooperar, compartiendo un momento de la vida y basándose en las interpretaciones comunes que hacen sobre diferentes situaciones. Esto quiere decir que los participantes en el acto comunicativo no seguirán las pautas de la acción estratégica en la que ellos buscan su propio éxito, sino que seguirán las pautas de la acción comunicativa cuya finalidad es entenderse mutuamente. En la comunidad ideal de comunicación de la que se nos habla en la ética del discurso, lo que se persigue es el consenso entre los participantes (París Albert, 2005: 188).

En este tipo de ética, tanto en el mundo subjetivo del participante o hablante como en el mundo social, la veracidad es muy importante. Por ello, se pueden criticar los actos de habla si se considera que el enunciado no es verdadero, si se duda respecto a si la intención del hablante es veraz, o se puede considerar un acto de habla no correcto si no cumple con las normas preestablecidas y aceptadas por todos los participantes. Otro punto importante de la ética del discurso es la responsabilidad, en tanto que todos los participantes deben asumir la responsabilidad de todo lo que dicen y las consecuencias que surgen de ello (París Albert, 2005: 189-190).

En definitiva, la ética del discurso, que también se conoce como la ética de la comunicación, tiene como base el discurso argumentativo (París Albert, 2005: 183).

\subsection{La eficacia cultural}

Siguiendo lo dicho en el apartado de la metodología, a continuación redactaremos los resultados del análisis del texto de los autores Eloísa Nos, Amador Iranzo y Alessandra Ferné, centrándonos en los significados de la eficacia cultural.

El estudio de la eficacia cultural se aplica y sustenta sobre una base muy importante que es la performatividad de los discursos, que se refiere, en pocas palabras, a las competencias que algunas palabras o expresiones tienen de convertirse en acciones que, finalmente, transforman la realidad. Este concepto de eficacia cultural tiene implícita «la capacidad de influencia sobre la opinión pública» (Nos, Iranzo y Ferné, 2012: 215).

Sin embargo, un primer paso hacia la eficacia cultural lo tiene la indignación, es decir, una emoción moral activadora, de responsabilidad, que empuja a la participación, a la investigación sobre aquello que indigna, y al empoderamiento. «En otras palabras, la eficacia comunicativa se entiende aquí como la capacidad de activar la sensibilidad moral de la ciudadanía (por medio de la indignación) como camino hacia una sabiduría cultural» (Nos, Iranzo y Ferné, 2005: 216). 
A lo largo de los resultados hemos podido ver que gran parte de los pilares sobre los que se basa la ética del discurso se encuentran en la filosofía con niñas y niños. Nada más empezar con el análisis de la vinculación entre las dos, nos podemos dar cuenta de que, de estas, el diálogo es la acción más presente e importante. Como bien se sabe, por una parte, la ética del discurso se desarrolla en torno al diálogo y, por la otra, la filosofía con niñas y niños utiliza el diálogo como metodología de trabajo.

Siguiendo con el análisis, hemos dicho que en la ética del discurso se busca una comunidad comunicativa ideal, una comunidad comunicativa en la que todos tengan voz, en la que todos puedan dar su opinión y esta sea absolutamente válida, independientemente de la persona. En las clases de filosofía con niñas y niños también se busca que ellos y ellas tengan voz, que den su opinión y juntos encontrar soluciones sobre diferentes situaciones de la vida, ya que, contrariamente a lo que desde occidente se ha intentado inducir, los niños y las niñas tienen capacidad crítica. Así pues, podemos decir que tanto en este tipo de ética como en esta metodología filosófica, se busca llegar a una comunidad comunicativa ideal.

En estas comunidades comunicativas, la acción comunicativa que se lleva a cabo parte de una situación planteada previamente, son interpretaciones comunes sobre diferentes situaciones. Está claro que en el caso de la filosofía con niñas y niños, se parte de un estímulo previo, una historia contada previamente cuya plasmación ayude a que los infantes tengan más empatía con los personajes. No obstante, si hay algo que une a la ética del discurso y a la filosofía con niñas y niños es el objetivo. Y este, o la finalidad del diálogo, no es que se llegue a una conclusión apoyada por todos los participantes, sino que se llegue a la verdad a través de la diversidad de opiniones. Esto quiere decir que los participantes no perseguirán su propio éxito, sino que tendrán como propósito final el entendimiento mutuo. Así pues, la comunicación persigue la empatía, el reconocimiento, el entendimiento mutuo y la búsqueda de la verdad.

Sin embargo, si hay algo que define y une estos dos modelos teóricos es que siguen las mismas pautas de cualquier debate imparcial en el que se pide que se escuche atentamente, que no se interrumpan las intervenciones de los compañeros, que no se impongan las ideas; se rechaza cualquier forma de ridiculización o falta al respeto de cualquiera de los participantes a la discusión. No hay que olvidar que, niños, niñas o adultos, todos tenemos responsabilidad sobre aquello que decimos, hacemos o callamos, puesto que tenemos la posibilidad de interpelarnos, es decir, podemos pedirnos cuentas por aquello que nos decimos, hacemos o 
callamos. Y esto, porque, como decíamos anteriormente, la acción comunicativa o el acto de habla busca el entendimiento; sin embargo, para que este se dé, se deben cumplir las pretensiones de validez del habla, es decir, la verdad, la inteligibilidad, la rectitud normativa y la veracidad.

Asimismo, hay que considerar que, tanto en la ética del discurso como en la filosofía con niñas y niños, se tienen en cuenta las diferencias de sexo, cultura, personalidad, religión, etc. De esta manera, por una parte, en la ética del discurso, como se ha mencionado anteriormente, las normas creadas por todos los participantes antes de la comunicación siguen el principio de universalización, según el cual estas se deben ajustar a las circunstancias de cada uno. Por otra parte, en la filosofía con niñas y niños se aprovecha esta diversidad de culturas, etnias, religiones, como una diversidad de percepciones sobre el mundo y una multitud de maneras de argumentar.

A continuación, como se ha mencionado en la introducción de este trabajo, me gustaría hablar sobre la eficacia cultural de la filosofía con niñas y niños a través de los resultados del análisis de los textos.

Si miramos los resultados extraídos sobre la filosofía con niñas y niños, nos damos cuenta de que sí que persigue una finalidad activa, de transformación de la realidad. Aunque estemos hablando de niñas y niños, esta filosofía aboga por un empoderamiento de estos infantes que, mediante las reflexiones filosóficas, puedan llegar a participar de forma activa en sus comunidades y naciones.

Sin embargo, como hemos mencionado anteriormente, el primer paso hacia la eficacia cultural es la indignación. En este sentido, se persigue que el alumnado de la filosofía sobre la que estamos hablando piense de una manera lógica, crítica y creativa. Por tanto, vemos que la creatividad está presente en la filosofía con niñas y niños, lo que podemos relacionar con otro pilar básico de la eficacia cultural: la participación. Los profesores y las profesoras, aparte de escuchar, tienen como objetivo empoderarlos para que, ulteriormente, se pase a la acción.

Por último, se puede observar que la filosofía con niñas y niños sí que goza de eficacia cultural, puesto que promueve un pensamiento reflexivo más allá de lo individual, encaminado hacia un bien común.

\section{Conclusión}

A lo largo de este trabajo se ha podido ver el estudio sobre la filosofía con niñas y niños y, después, por una parte, la relación y fusión de esta con la ética del discurso y, por otra, el análisis de su eficacia cultural. 
De esta manera, se ha podido observar que tanto la filosofía con niñas y niños como la ética del discurso tienen como pilar básico el diálogo. Continuando con el análisis de las dos, hemos visto que tienen como aspiración una comunidad comunicativa ideal, en la que todos los participantes tengan voz, puedan aportar sus opiniones y sean escuchados.

Asimismo, en este estudio también pudimos ver que en ninguno de los dos casos la finalidad que se persigue es un objetivo individual o estratégico, sino que se quiere llegar a la verdad mediante la diversidad de opiniones, el entendimiento mutuo y la empatía. No obstante, los dos modelos teóricos que estamos considerando siguen las mismas pautas que cualquier debate imparcial, en el que el respeto mutuo hacia las opiniones del otro o hacia su turno de palabra son las pautas que dirigen el diálogo. Y esto es así porque tenemos responsabilidad sobre todo lo que decimos, hacemos 0 callamos, ya que tenemos la capacidad y la posibilidad de interpelarnos los unos a los otros.

Si pasamos a la otra parte analizada en este texto, la eficacia cultural de la filosofía con niñas y niños, hemos podido observar que esta tiene como finalidad última la trasformación de la realidad. Es una filosofía que se propone empoderar a niñas y niños para que, posteriormente, puedan participar activamente en sus sociedades. Para llevar a cabo este propósito se empuja a los infantes hacia un pensamiento crítico, lógico y creativo.

Como conclusión se puede decir que la filosofía con niñas y niños sí que tiene una eficacia cultural, teniendo en cuenta que se les empuja hacia un pensamiento reflexivo sobre el bien común. Sin embargo, esta filosofía puede dar la imagen de que se queda bastante en la reflexión, sin llegar a la práctica, lo que veo como una posible limitación de esta. Considero que el profesorado, después de pasar sobre el proceso de reflexión y debate con el alumnado, no solo debe empoderarlo teóricamente para que en un futuro pueda actuar para transformar la realidad, sino que deben implicarlos físicamente en casos concretos de su propia sociedad. De esta manera, aunque sean niñas y niños, se verán productivos para su entorno, lo que los empoderará más que cualquier reflexión crítica.

\section{Bibliografía}

Dussel, Enrique. 1996. "La ética de la liberación ante la ética del discurso". Isegoría: Revista de filosofía moral y política 13: 135149.

Ferrer Rodríguez, Guillermina. 2012. «Filosofía para niños. Cómo acercar la filosofía a niños y niñas». Fòrum de Recerca 17: 21-34. 
Haynes, Johanna. 2004. Los niños como filósofos. El aprendizaje mediante la indagación y el diálogo en la escuela primaria. Barcelona: Paidós Educador.

Martínez Guzmán, Vicent. 2004. «Diálogo». En Enciclopedia de paz y conflictos, editado por Mario López Martínez, 302-303. Granada: Publicaciones de la Universidad de Granada.

Nos Aldás, Eloísa, Amador Iranzo y Alessandra Farné. 2012. "La eficacia cultural de la comunicación de las ONGD: los discursos de los movimientos sociales actuales como revisión». CIC. Cuadernos de Información y Comunicación 17: 209-237.

París Albert, Sonia. 2006. La transformación de los conflictos desde la Filosofía para la Paz. Tesis doctoral. Castelló de la Plana: Universidad Jaume I.

Siurana, Juan Carlos. 2007. «La ética del deporte desde la justicia como igualdad de oportunidades en la ética del discurso». Quaderns de Filosofia i Ciència 37: 79-90. 